\title{
A Liberdade em Estátua: uma odisseía no Novo Mundo
}

https://doi.org/10.30779/cmm_metalica_54_02

\author{
1 Não como o gigante bronzeado de grega fama, \\ Com pernas abertas e conquistadoras a abarcar a terra; \\ Aqui nos nossos portões banhados pelo mar e dourados pelo sol, se erguerá \\ Uma mulher poderosa, com uma tocha cuja chama \\ É o relâmpago aprisionado e seu nome \\ Mãe dos Exílios. Do farol de sua mão \\ Brilha um acolhedor abraço universal;'?
}

Emma Lazarus*

Decorrido que estava já quase um século depois da Declaração de Independência dos Estados Unidos, datada de 1776 e cujo mentor principal seria Thomas Jefferson (com interesses declarados na prática arquitetónica e 3ํㅜ presidente do país), tornava-se socialmente imperativo deixar lastro visível de tal acontecimento de valor universal, que simbolizava o princípio de liberdade, de igualdade e de fraternidade. Ideais amplamente professados pela França e pelos quais heroicamente se bateu mesmo no final do século XVIII, num movimento contagiante iniciado com a célebre Tomada da Bastilha em 14 de julho de 1789. Pelo papel que estes dois países - EUA e França - ocupam na cena internacional de estados fundadores da democracia, a que não será alheio o pensamento político de Alexis de Tocqueville (1805-1859), assume particular relevância e interesse um empreendimento como a Estátua da Liberdade, enquanto sentinela do mundo ocidental.1

A Liberdade lluminando o Mundo é, indubitavelmente, a mais ousada realização de Auguste Bartholdi, tendo ficado conhecida como a Estátua da Liberdade. Constituindo um ícone e uma marca identitária dos EUA, nem por isso favoreceu o conhecimento planetário do seu autor, apesar de na efervescência do acontecimento esta fosse conhecida como a Estátua de Bartholdi. ${ }^{2}$

Tradicionalmente, na maior parte dos casos os monumentos são evocativos de determinadas situações, tais como personalidades, conflitos ou conquistas, mas, no caso específico esta estátua é testemunho de um ideal que depois é simbolicamente transportado e

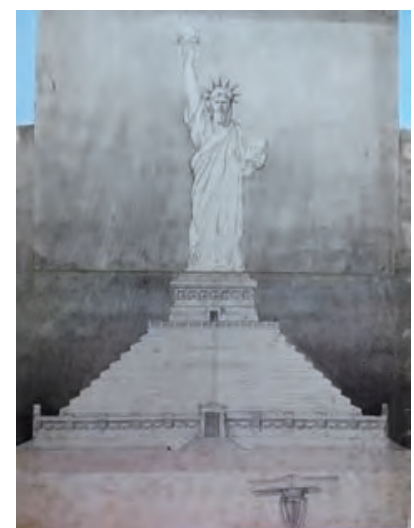

1. Auguste Bartholdi, Projeto do Pedestal Piramidal da Liberdade Iluminando o Mundo (c. 1880). transforma-se como um imaginário associado a toda uma nação. Este monumento foi um empreendimento que uniu vontades e receitas em dois países, ficando a estátua a cargo do povo francês e o pedestal nas mãos dos americanos, com projeto do famoso arquiteto americano Richard Morris Hunt, fazendo com que em cada um dos continentes se desenvolvesse uma comissão específica para reunir os montantes suficientes para a sua concretização. ${ }^{3}$ No arranque da tentativa de financiamento nos EUA, contrariando expectativas mais otimistas, a sociedade americana não aderiu ao projeto. A contaminar essa difícil tarefa foi desenvolvida uma conotação do empreendimento com a cidade de Nova Iorque, condicionando a recolha de fundos fora desta geografia. ${ }^{4}$ Pela posição que a estátua ocupava, numa ilha, rebatizada como Ilha da Liberdade - inicialmente Ilha de Bedloe - e num amplo porto natural, foi, durante o período das grandes emigrações europeias para os EUA, considerada um marco ostentatório da esperança, da tolerância, de coesão e de agregação. Nesse sentido, aquele monumento foi-se constituindo como um espaço de memória, evocativo de princípios constitucionais, afastando-se cada vez mais da sua génese inicial de construção e transformando-se num ícone da América.

\footnotetext{
* Excerto do poema New Colossus, escrito em 1883 com o propósito de ajudar a angariação de fundos do pedestal da Estátua da Liberdade e que está gravado numa placa colocado no pedestal em 1903 (Ema Lazarus, Selected Poems and Other Writings, editado por Gregory Eiselein, Broadview Literary Texts, Peterborough, p. 233 e nota 1). Sugerimos a leitura de Viano, Francesca Lidia, Sentinel, The Unlike Origins of the Statue of Liberty, Harvard University Press, Cambridge, 1986 


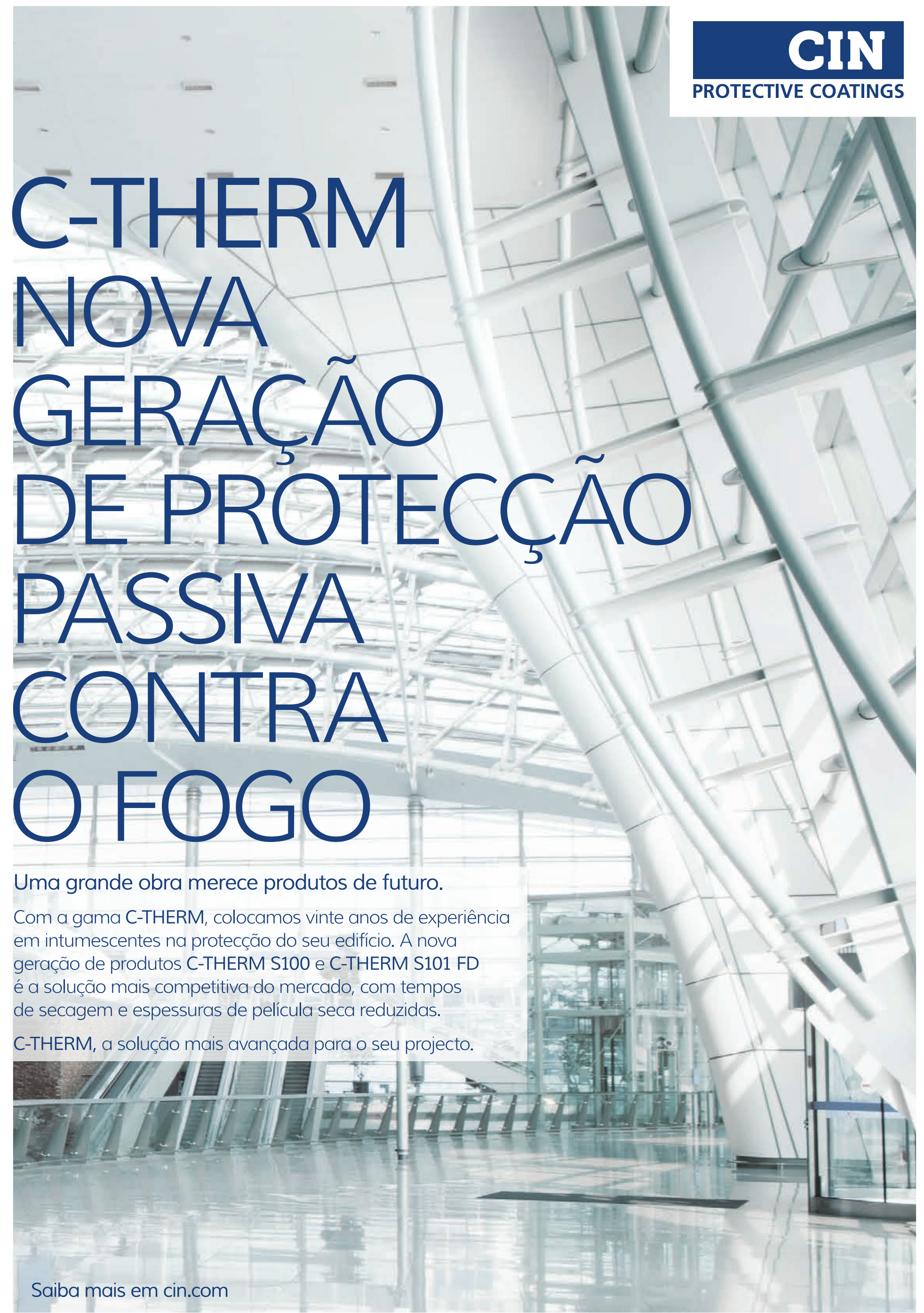




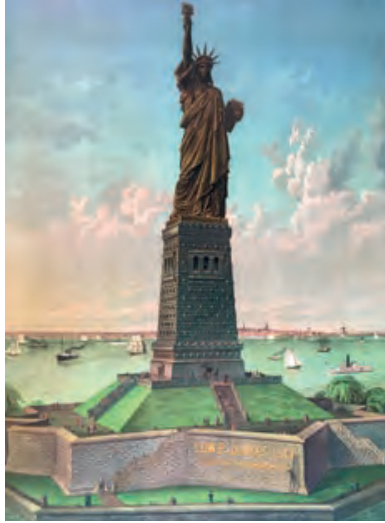

2. Auguste bartholdi, Cromolitografia, 1884.

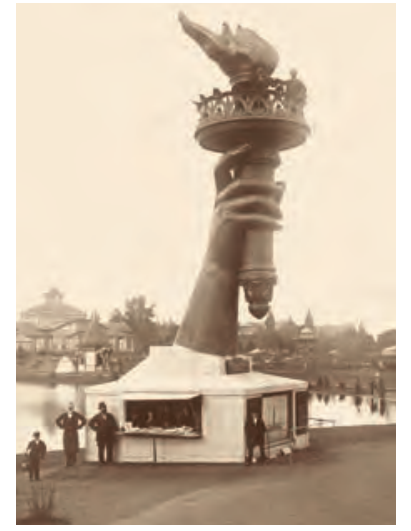

3. Foto de braço e da tocha da Estátua da Liberdade exposta na Exposição Universal de Filadélfia em 1876.
Na segunda metade do século XIX assistiu-se a um período onde se ensaiam inúmeros artefactos que pretendem ultrapassar as alturas protagonizadas pela desenvoltura da arquitetura gótica, sendo muito desse esforço feito em território americano. O final do século XIX foi um período relevante para e exercício da construção em altura, nas suas diversas vertentes funcionais, dado a qualidade da produção de ferro e da sua gradual banalização de uso na arquitetura. Um desafio como a Estátua da Liberdade tinha para além da dificuldade de financiamento dado os enormes custos envolvidos, o problema da superação de um conjunto muito elevado de questões técnicas e estruturais dado tratar-se de um projeto que não tinha nenhum termo de comparação. As condições e o espaço físico onde se pretendia implantar o colosso significavam um enorme desafio tecnológico, mas pela exposição que tal projeto tinha, poderia em caso de fracasso, provocar a desgraça dos seus executores. Se na aparência este seria um risco calculado, na prática tratava-se de um enorme desafio que colocava em jogo os conhecimentos mais avançados e certamente constituía um feito notável em termos de engenharia e da publicitação do potencial associado às estruturas metálicas. Dada a dimensão deste colosso, muitas das vezes, devido às questões de escala, é recorrente o uso da analogia de um confronto entre formigas e um titã, de Liliputianos contra Golias. ${ }^{5}$

Naquela época, a estátua batia certamente um record mundial pela sua altura e, apesar de corresponder a uma casca, composta por placas rebitadas, com esqueleto metálico, era um desafio de engenharia notável, quanto mais não seja porque se estava a falar de duzentas e cinquenta e quatro toneladas de metal, das quais oitenta e uma eram de cobre. ${ }^{6}$ Em termos de passado, sabe-se que Bartholdi conhecia com algum detalhe outras experiências de estátuas, sendo de destacar o Colosso

Hayden, Richard Seth e Despont, Thierry, Restoring the Statue of Liberty, McGraw-Hil Book Company, Nova lorque, 1986, p. 46

Moreno, Barry, The Statue Liberty Encyclopedia, Simon \& Schuster, Nova lorque, 2000, p 75. de San Carlo Borromeo ${ }^{7}$ construído entre 1614 e 1698, que o escultor havia visitado em 1869 aquando de uma passagem por Arona no contexto de uma sua viagem ao Egito. ${ }^{8}$ Este colosso, feito com chapas moldadas em cobre foi até durante bastante tempo a maior estátua deste género, tendo sido somente superada no século XIX, primeiro pela Estátua de Arminius ${ }^{9}$ em Detmold na Vestefália e, imediatamente, depois pela Estátua da Liberdade. No caso da estátua alemã, ela foi construída entre 1838 e 1875 e o seu autor, Ernst von Bandel, recorre ao subterfúgio da espada empunhada sobre um braço elevado, permitindo uma maior altura do monumento. Este meio ardiloso também seria utilizado por Bartholdi através do recurso ao braço elevado ostentando uma tocha. A estátua foi a construção mais alta de Nova lorque, até ser suplantada em 1897 pelo St. Paul Building, do arquiteto George Browne Post, infelizmente demolido em 1958.

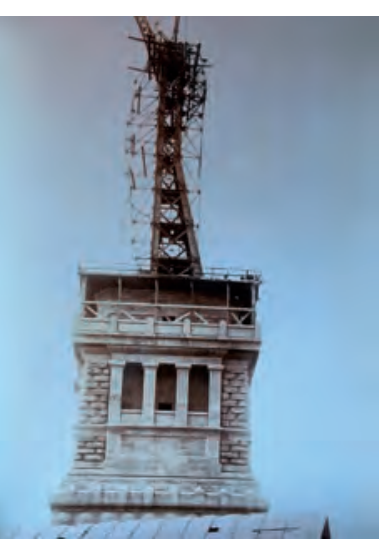

4. Autor desconhecido, A Estátua da Liberdade em Nova lorque: assemblagem da estrutura metálica no pedestal, 1886
Uma das situações mais interessantes da Estátua da Liberdade é sem dúvida a solução estrutural desenvolvida por Eiffel, que se assemelha a uma espécie de esqueleto a que foi adicionada uma capa. Sendo muito importante a questão das fundações dado a carga do colosso metálico, é particularmente relevante o modo como foi concebida a estrutura interior de suporte. Esse esqueleto é composto por três partes distintas mas que se complementam. Uma primeira que corresponde a um pilone metálico central, composto por quatro pilares metálicos, que constitui a torre principal de sustentação; um suporte secundário constituído por treliças que vão definir uma conformação entre a estrutura principal e o volume interior da estátua; uma terceira, formada por barras retangulares $(50 \times 8 \mathrm{~mm})$ que - correspondendo a uma espécie de molas - fazem a ligação entre a estrutura secundária e a camada de envelope em folha de cobre que define a estátua, permitindo a transmissão da ação do vento da carapaça exterior para o pilone central. ${ }^{10}$ Na definição da volumetria da estátua, o recurso a um revestimento enrugado, correspondendo a um traje, foi certamente uma escolha que favoreceu o caráter portante da estátua. Na realidade a utilização de

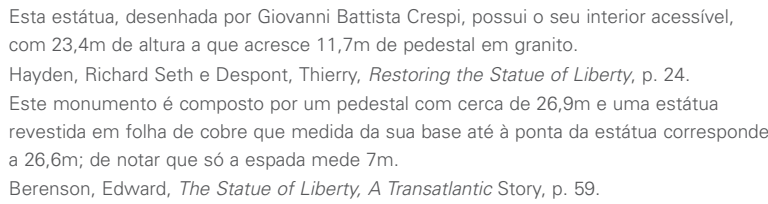


um vestido plissado correspondendo a uma toga romana a que foi sobreposto uma estola, foi decididamente um subterfúgio que ajudou em muito a conferir rigidez a todo o invólucro exterior. Um invólucro que se pretendia que tivesse algum nível de autonomia relativamente à estrutura interior de modo a poderem absorver-se dilatações, contrações e oscilações, tanto devido às amplitudes térmicas como à ação dos ventos.

Uma das maiores incógnitas em torno da Estátua da Liberdade é a identidade do seu modelo. Não tendo esta resposta sido clarificada em vida pelo autor, as escolhas sempre andaram pelo núcleo de pessoas mais próximas, cuja hipótese mais credível seria a sua própria mãe, Charlote Bartholdi, ou a dedicada esposa Jeanne-Emilie de Puysieux. No entanto segundo parece, a face enigmática e com nariz romano pode ser de Sarah Coblenzer (mais conhecida como Sarah Salmon devido ao casamento com André Salmon), que havia impressionado Bartholdi durante uma visita ao seu atelier em Paris e levado a reconhecê-la como uma incarnação da imagem que este pretendia para eternizar a liberdade. ${ }^{11} \mathrm{O}$ que esta história tem de mais curioso é

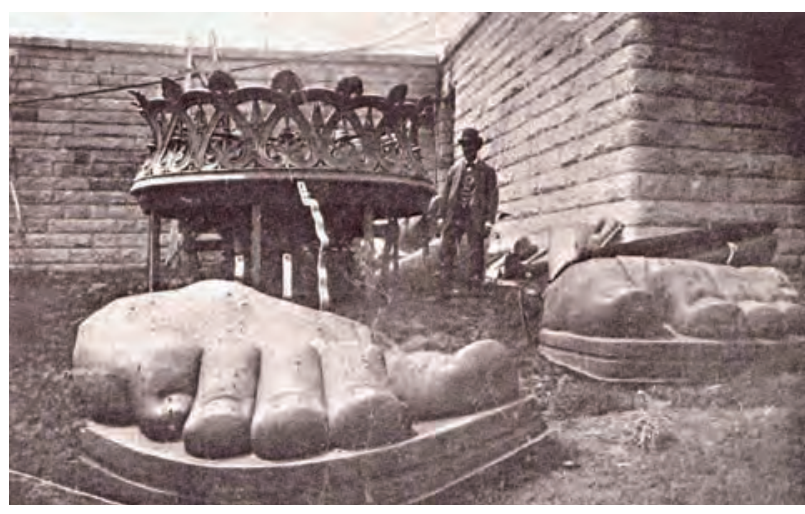

5. Pé e tocha da Estátua da Liberdade junto ao Forte Wood da IIha de Bedloe (c. 1885-86).

precisamente a circunstância de Sarah ter ascendência familiar alemã e, sobretudo, ter nascido em Nova lorque. Pelo que se sabe, Bartholdi sempre pretendeu que a estátua e a sua face constituíssem um símbolo e não um retrato, motivo porque nunca revelou publicamente quem havia constituído o seu modelo, limitando-se sempre a fazer considerações de caráter genérico e pouco objetivo.

Se do lado francês, a projeto de implementação da Estátua da Liberdade era um assunto sério, de difícil
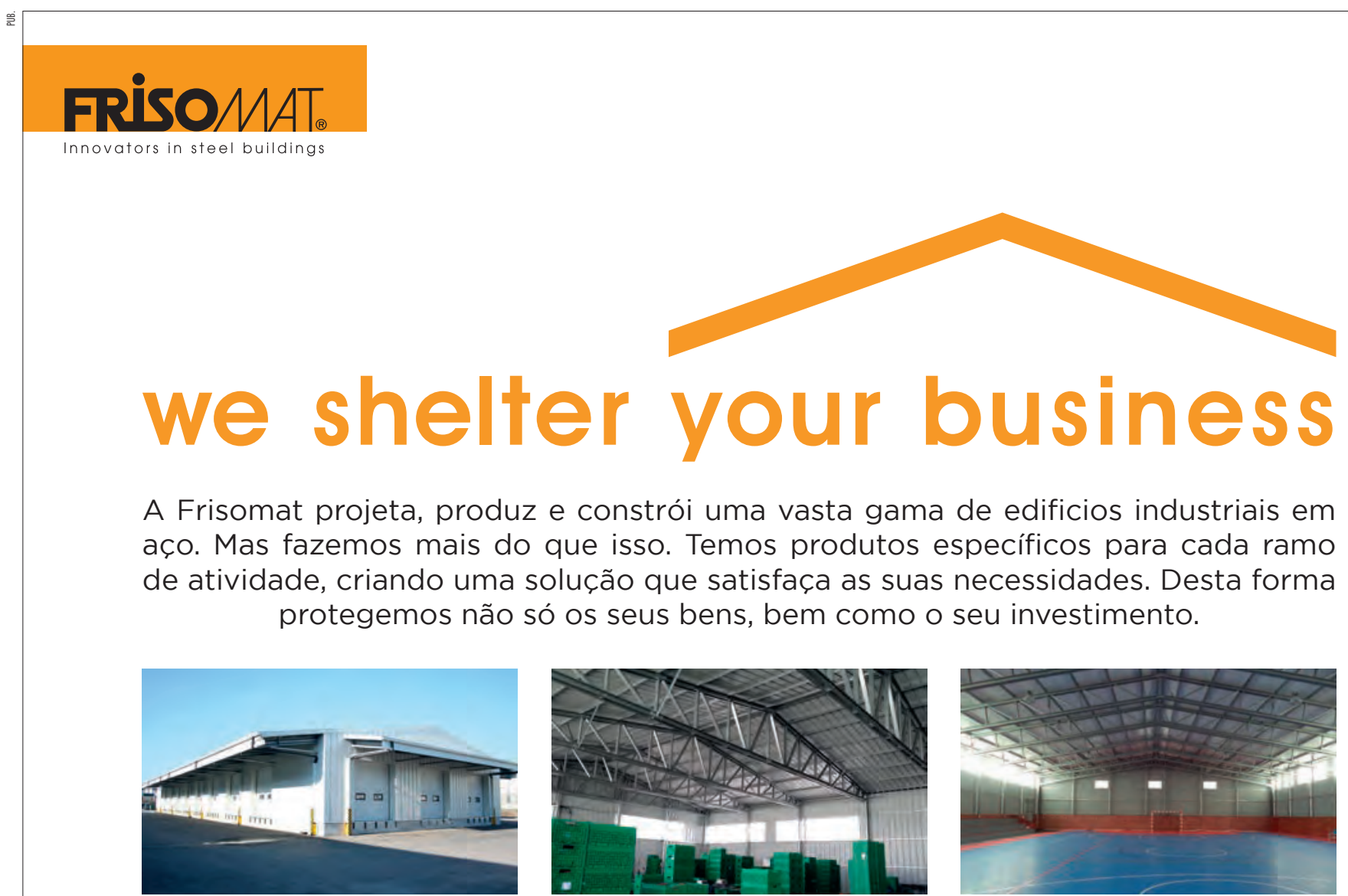

A Frisomat projeta, produz e constrói uma vasta gama de edificios industriais em aço. Mas fazemos mais do que isso. Temos produtos específicos para cada ramo de atividade, criando uma solução que satisfaça as suas necessidades. Desta forma protegemos não só os seus bens, bem como o seu investimento.

Frisomat S.A. | +(351) 234940210 | info@frisomat.pt | www.frisomat.pt 


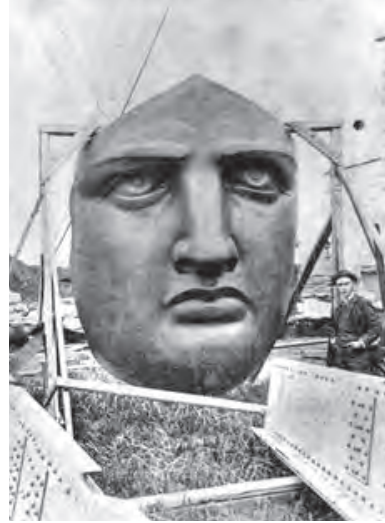

6. Face da Estátua da Liberdade, Ilha de Bedloe (c. 1885-86).

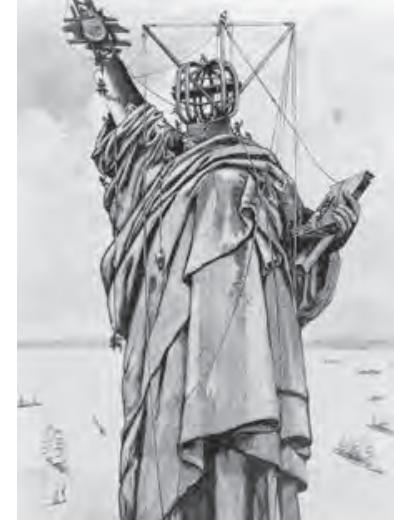

7. Henri Thiriat, A Estátua da Liberdade em Nova lorque: o Final da Assemblagem in L'lllustration, outubro de 1886

consumação, do lado americano, apesar de ser uma terra com múltiplos milionários, revelou-se ser uma tarefa hercúlea e se não fosse a dedicação de Joseph Pulitzer $^{12}$, pondo o seu jornal, o New York World, ao serviço da causa, tudo não teria passada de um sonho, já que foi grande o desfasamento do desenvolvimento de trabalhos num e noutro lado do Atlântico. Como se sabe o embarque dos contentores com as diversas partes da estátua havia saído na fragata da marinha francesa no mês de maio de 1885 de França e somente chegado, com atraso, a 17 de junho de 1885 a Nova Iorque. O atraso deveu-se à necessidade de um reabastecimento intermédio de carvão e de mantimentos na ilha do Faial, nos Açores, situação não programada, mas imperativa devido, sobretudo, ao mau tempo. ${ }^{13}$

Para lançar o processo da construção do monumento no contexto dos EUA e para manter vivo esse projeto foi necessária a deslocação de Bartholdi ao continente americano. Assim da parte do escultor francês e tendo como denominador comum a Estátua da Liberdade, foram realizadas cinco viagens transatlânticas, entre 1871 e 1893. A primeira, após doze dias em alto-mar, com desembarque no porto de Nova lorque no dia 21 de junho de 1871, permitiu-lhe observar um proeminente rochedo, fortificado, oferecendo-se desde o primeiro momento como um sítio potencial para a colocação da sua estátua. No entanto este local tinha como contrariedade o facto de no sítio ambicionado - Ilha de Bedloe - existir um forte militar. ${ }^{14}$

A viagem mais proveitosa foi decididamente a realizada no contexto da Exposição Universal de Filadélfia, em 1876, permitindo a Bartholdi uma deslocação pelo território americano durante um período alargado de nove meses. Esta viagem, com chegada a 18 de maio a
Filadélfia, serviu para aí mostrar um troço da Liberdade, com cerca de 10 metros de altura, correspondendo ao antebraço que tomava na mão a tocha, garantindoIhe uma notoriedade, dado o troço ser visitável e conseguindo reunir uma dúzia de pessoas no balcão que coroava o fuste. Este sucesso foi corroborado pela inauguração em Nova lorque da sua estátua Lafayette arrivant en Amérique, oferecida pelo governo francês à cidade americana. Depois de Filadélfia, seria transportado para Nova lorque o fragmento da estátua, confirmando-se aí a popularidade do acontecimento. A 4 de julho de 1876, data do centenário da Independência dos EUA e não havendo cumprido a sua vontade de ter terminado este ambicioso projeto, Bartholdi teve a oportunidade de ver exposta ao lado do edifício do New York Club em Madison Square, uma imagem gigante iluminada representando a estátua, confirmando o entusiasmo e a possibilidade de viabilização daquilo que durante muito tempo foi uma utopia. O troço que se manteve ainda algum tempo em exposição, seria devolvido para França em agosto de 1882, para incorporar a estátua original. ${ }^{15}$ Esta parte da estátua havia sido desenvolvida ainda sob a orientação do visionário Viollet-le-Duc, que propagandeava a utilização do ferro como solução útil e acertada para a arquitetura, seja ela nova ou em situação de reabilitação, preconizando a utilização em massa das soluções metálicas.

No entanto apesar de todos os esforços de Bartholdi, tardava o reconhecimento oficial do projeto e somente em 22 de fevereiro de 1877, no contexto da comemoração do aniversário de George Washington o Congresso dos EUA, por unanimidade, daria suporte moral para esta grandiosa obra. Este apoio não seria suficiente já que tornava-se imperativo a definição de uma estratégia e de um instrumento de suporte que permitisse a construção do pedestal da estátua e era encargo sob a responsabilidade americana. Em março de 1883 e estando a estátua praticamente concluída em Paris, o Congresso chumba a disponibilização de um fundo para apoio à construção do pedestal. Uma tentativa de angariação de fundos para o projeto foi desenvolvida por Joseph Pulitzer, através do seu jornal New York World. Este esforço, quase infrutífero, em novembro de 1883, havia recolhido cerca de uma centena de dólares quando aquilo que estava em causa na altura, segundo estimativas otimistas, era de uma ordem de grandeza de centena de milhar de dólares. Com vista à construção do pedestal, os trabalhos de escavação haviam começado em abril de 1883 e terminado em junho, a que se seguiram em outubro desse mesmo ano, o início das fundações. ${ }^{16}$

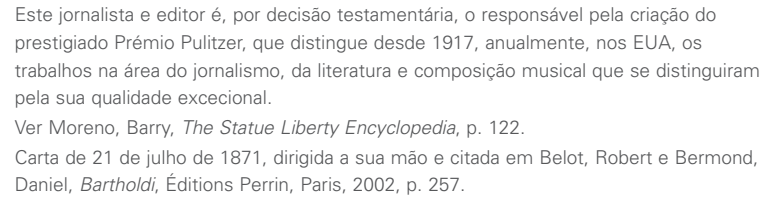


No ano de 1884, a construção das fundações do pedestal segue o seu rumo, lento, sob o controlo do engenheiro Charles P. Stone e com projeto de Richard Morris Hunt. Este arquiteto, que tinha um gosto particular pela arte monumental egípcia, utilizou como base para o seu projeto, os estudos elaborados previamente por Bartholdi. ${ }^{17}$ Nos primeiros estudos desenvolvidos por Bartholdi, ainda sem a contratação de Hunt, é notória a influência da arquitetura précolombiana, querendo talvez o escultor ensaiar formas e um tipo de edificação que pudesse ter uma génese identificada com o continente americano. A proposta de Hunt, só seria apresentada à Comissão Americana ${ }^{18} \mathrm{em}$ 31 de julho e aprovada em 7 de agosto de 1884. Com as suas proporções gigantescas, o pedestal apresenta um desenho clássico, com uma estrutura em betão forrada a granito originário da Ilha de Leete, no Connecticut. Atendendo às dimensões da estátua, o projeto do embasamento foi uma questão muito importante e relativamente vital para o sucesso do processo, quer por questões funcionais e estruturais, como também por questões estéticas de integração deste no conjunto. ${ }^{19}$

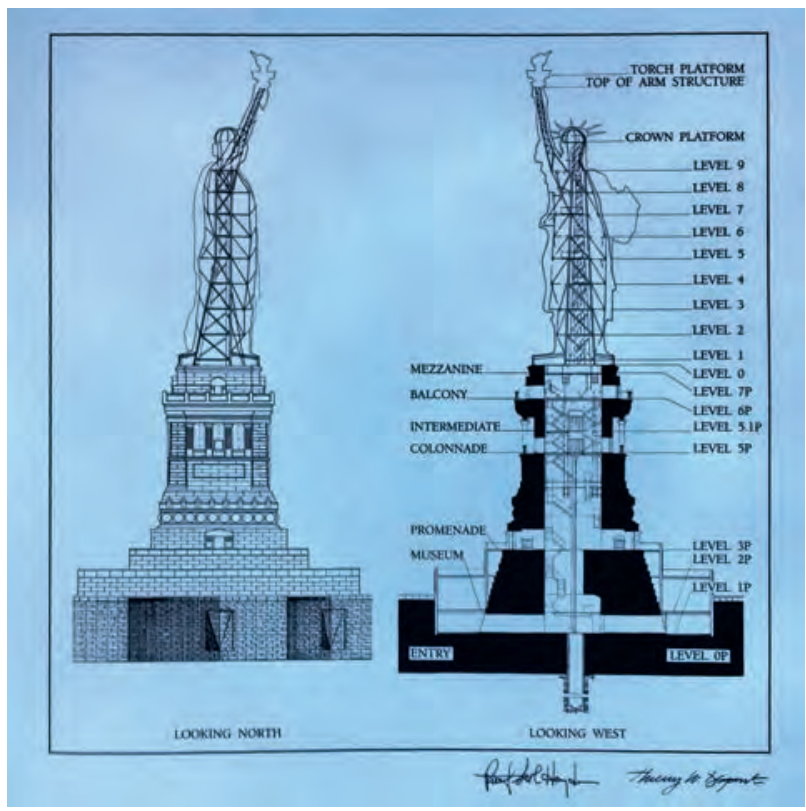

8. Alçado e corte da Estátua da Liberdade produzidos no âmbito do contexto do projeto de reabilitação dos anos oitenta do século passado.

O pedestal, devido à sua forma foi múltiplas vezes associado a um farol, particularmente ao de Alexandria, uma das sete maravilhas do mundo. Este pedestal foi construído sobre as paredes do Fort Wood, cujo desenho base correspondia a uma configuração estrelada, com onze bicos, decorrente de uma

\footnotetext{
Hayden, Richard Seth e Despont, Thierry, Restoring the Statue of Liberty, p. 33. O American Commitee era um ramo da Franco-American Union (fundada por Edouard Laboulaye com o intuito de financiar a Estátua da Liberdade e o respetivo pedestal). Para se ter uma ideia mais aproximada das várias variantes do pedestal desenvolvidas por Bartholdi e Hunt, consultar Stein, R. Susan, "Richard Morris Hunt, architecte du piédestal", in La Statue de la Liberté, L'Exposition du centenaire, Musée des Arts Décoratifs, Paris, 1986, pp. 192-199. Para uma perceçāo da obra de Hunt, consultar Stein, R. Susan (edited dy), The Architecture of Richard Morris Hunt, The University of Chicago Press, Chicago, 1986
}

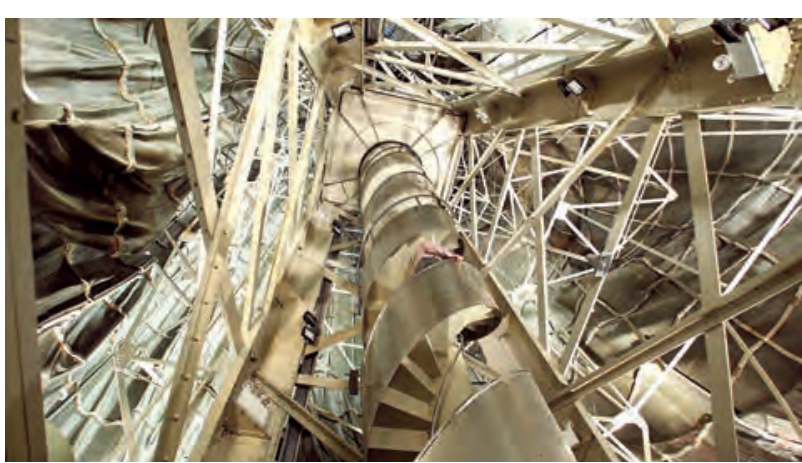

9. Foto atual do interior da Estátua da Liberdade, com vista da escada central helicoidal e estrutura de suporte.

fortificação construída entre 1807 e 1811. A decisão da cedência da ilha de Bedloe para a implantação da Estátua da Liberdade, sob proposta inicial e determinação de Bartholdi, foi oficializada pelo general William T. Sherman, em 1877, após pedido expresso do presidente Rutherford Hayes, já que nessa época o forte não possuía qualquer função defensiva. ${ }^{2}$

Na primavera do ano de 1885 as obras continuam a uma cadência muito baixa, com forte carência de recursos e com uma opinião pública muito pouco motivada para o empreendimento. A partir de março de 1885 - e durante cinco meses - é ensaiada uma nova tentativa de angariação de fundos por parte de Pulitzer no seu jornal. Assim, lentamente e porque se foram associando ao projeto muitas outras iniciativas como peditórios, concertos oferecidos e exposições, foram crescendo o número de dádivas em numerário de pessoas, muitas elas anónimas. Todavia, em termos de financiamento do empreendimento o verdadeiro "ovo de Colombo" foi a publicação do nome das pessoas que fizessem donativo nos páginas do The World, tornando muito aliciante e com particular sucesso a campanha de recolha de fundos.

A terceira viagem de Bartholdi aos EUA que aconteceu entre 4 e 25 de novembro de 1885, será decorrente do decurso dos trabalhos de construção do pedestal, podendo este avaliar todo o processo previsto para a remontagem da estátua que estava dispersa pela Ilha de Bedloe desde junho desse ano. Somente em 16 de maio de 1886, quase um ano depois da chegada da estátua aos EUA, ficava o pedestal em condições de poder iniciar nova fase de trabalhos. ${ }^{22}$ No processo final de montagem da estátua, que ocorreu principalmente durante o verão de 1886, para além de um cuidado na sobreposição de cada uma das peças, tentando assegurar o máximo de regularidade da superfície, existiu a preocupação de que todo o complexo processo de rebitagem fosse feito pelo interior, aumentando o efeito de unidade do conjunto, como se toda a estátua

Moreno, Barry, The Statue Liberty Encyclopedia, pp. 21 e 91

Mitchell, Elizabeth, Liberty Torch, p. 191.

Stein, R. Susan, "Richard Morris Hunt, architecte du piédestal", p. 199 


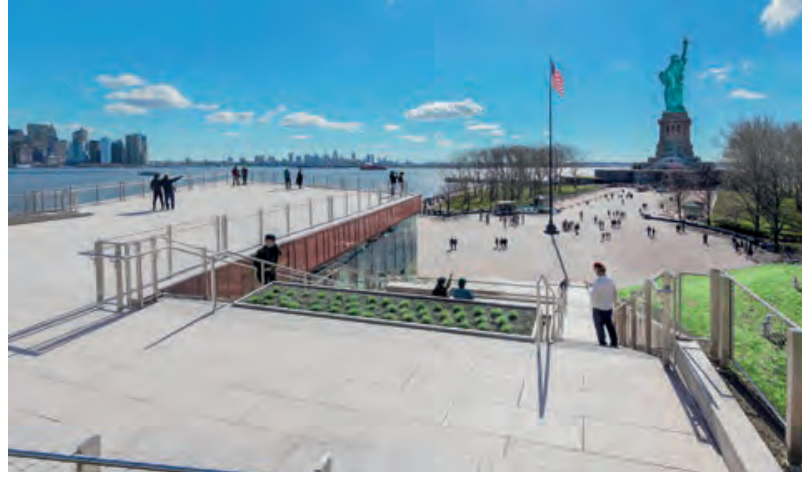

10. imagem da plataforma do State of Liberty Museum com vista da Estátua da Liberdade, obtida em 2019.

fosse feita de uma só vez e por um material contínuo. ${ }^{23}$ Para além desta situação, foi preciso assegurar que os rebites apresentassem folgas suficientes para assegurar as inevitáveis dilatações decorrentes da amplitude térmica anual, transformando esta tarefa numa espécie de trabalho especializado de alfaiataria onde as costuras devem ser robustas mas discretas. ${ }^{24}$ De referir que enquanto em Paris a montagem havia sido feita com recurso a um andaime exterior, as condições de montagem na Ilha de Bedloe não permitiam que fosse montado qualquer andaime, sendo os trabalhos, por isso, mais complexos e perigosos.

Originalmente a estátua estava prevista ser iluminada, ainda com querosene, produto líquido à base de petróleo. Considerando que em 1879 Thomas Edison apresentou a primeira lâmpada incandescente comercializável, e posteriores desenvolvimentos da tecnologia, permitiram que um mês antes da inauguração a tocha tivesse sido eletrificada e melhorando, inexoravelmente, a sua imagem e vista noturna. ${ }^{25}$

A 25 de outubro de 1886, uma delegação francesa, que incluía Bartholdi e Lesseps chegam a Nova lorque mesmo a tempo da inauguração da estátua da liberdade, constituindo esta a quarta deslocação do escultor a território americano. As cerimónias, com data de 28 de outubro, com enorme aparato militar, naval e sobretudo discursivo, com forte presença de público, foram lideradas pelo presidente Grover Cleveland, num dia tempestivo e com muita chuva. ${ }^{26}$ Este era certamente um dia que assinalava magistralmente o fim de um ciclo.

De um modo geral, dada a qualidade da solução construtiva desenvolvida para a Estátua da Liberdade, esta tem superado as condições adversas a que está sujeita, com uma idade superior a um século

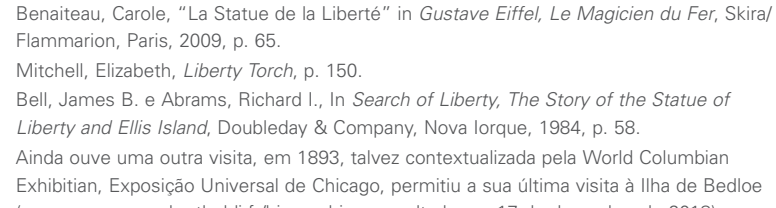

e não estando muito distante o acrescento de mais meio século à sua existência. Neste longo período, e coincidindo com momentos relevantes, a estátua foi objeto de duas grandes intervenções de reabilitação. Uma primeira no contexto dos cinquenta anos, em 1936 e que para além de problemas de corrosão, teve a implementação de um novo sistema de iluminação, assunto que foi claramente um problema desde o início da obra e um segundo, bastante mais profundo e que ocorreu nos anos de 1985 e 1986, tendo certamente em vista as comemorações de um século de existência.

Neste última intervenção, para além da natureza dos trabalhos realizados, foi particularmente relevante o aparato criado para a sua concretização. Aquilo que sobressaiu para além do natural condicionamento da visita à estátua foi um enorme andaimado que envolveu todo o volume da estátua e que praticamente tapou a Liberdade. Esta obra, de singular especificidade e de modo a salvaguardar a integridade da estátua, obrigou a que essa estrutura fosse totalmente independente da couraça, dado que as alturas envolvidas e os ventos da zona, poderiam colocar em causa o monumento. Ora, no contexto da reabilitação dos anos oitenta do século passado, a parte estrutural que estava em piores condições eram as barras chatas de ligação à couraça exterior da estátua devido às sucessivas ações climatéricas adversas e sobretudo porque o processo de corrosão no contacto entre o cobre e o ferro estava em estado bastante avançado. De notar que cientes deste problema, Eiffel havia utilizado o amianto como material de transição. Complementarmente e pensando nas dilatações, no interior, na zona da ligação havia sido criado interiormente um invólucro de cobre em forma de $U$ que selando as barras quadrangulares as autonomizavam relativamente à casca da estátua, facilitando contrações e dilatação. Assim dado o desgaste das camadas de amianto e cumulativamente conhecidas as suas propriedades cancerígenas, a remoção deste material foi uma das prioridades da intervenção. Um outro problema com alguma gravidade foi a falência de muitos dos rebites das chapas, provocando deslocamentos destas e consequentemente inúmeros pontos de entrada de humidades com sérios prejuízos para a estrutura em ferro. ${ }^{27}$ Nesse contexto, procedeu-se à reformulação do espaço de acesso, criando um local provisório para exposição dos originais da tocha e da chama que foram substituídos. O local definitivo para estes elementos originais seria o Statue of Liberty Museum ${ }^{28}$ projetado pelo conhecido gabinete de arquitetura nova-iorquino FXCollaborative, e que se situa em ponto da ilha oposto à estátua. No caso específico deste projeto, pretendeu-se a diluição do volume construído na paisagem, criando-se um plano 
inclinado que depois se prolonga para a cobertura com recurso a uma superfície vegetal e cuja cota máxima não excedesse o nível do piso da plataforma da Estátua da Liberdade. Esta intervenção de enorme sensibilidade estética teve ainda o cuidado de utilizar a mesma paleta de materiais do monumento. Ou seja, o mesmo tipo de granito, o cobre para o revestimento de fachada e o aço como elemento estrutural dominante.

Se hoje a Estátua da Liberdade existe enquanto realidade, tal empreendimento só foi possível graças à determinação férrea de um homem que soube congregar todo um conjunto de vontades, associando um projeto artístico a uma proeza notável de engenharia e detentor de capacidades diplomáticas excecionais. Sem estas particularidades, sem todos estes atributos, estamos certos que tal obra grandiosa não teria passado de mais um projeto megalómano. Na realidade, Bartholdi foi o grande timoneiro de um projeto que aproximou dois continentes e que, genialmente transformou um sítio quase banal num lugar memorável, num lugar transcendente, que se afirmou como uma marca indelével e identitária. No caso concreto foi o acontecimento da independência do EUA que constituiu a base fundacional para um monumento que pretendia tornar eterno a relação de fraternidade entre dois povos,

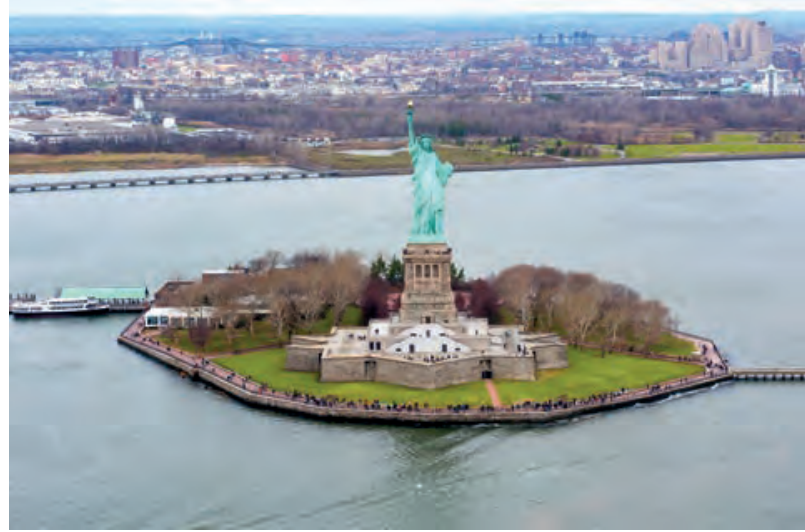

11. Vista aérea da IIha de Bedloe da autoria de Ramey Logan obtida em 2014.

mas na verdade dadas as contingências posteriores e o valor que tal construção adquiriu, esta tornou-se em quase um seu equivalente.

Apesar de utilizada a frase num contexto diferente, apetece dizer que "Neste caso, o acontecimento precede o monumento, mas ao mesmo tempo o monumento faz o acontecimento" 29 .

Belot, Robert e Bermond, Daniel, Bartholdi, p. 210.

\section{㾞 \\ Próximo nível de integração Tekla}

\section{Trimble.

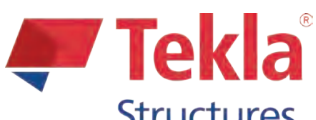

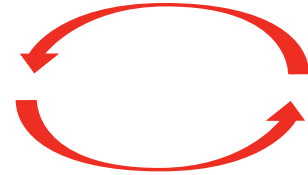

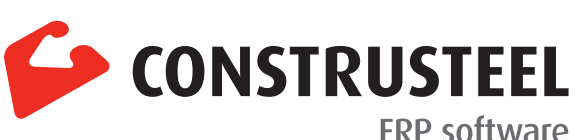

\section{Tekla Apps:}

- Nesting de material diretamente do modelo Tekla;

- Calcular graficamente: Orçamentação diretamente do modelo Tekla;

Integração do progresso da produção no modelo Tekla;

- Preparação do trabalho: ordens de fabrico, materiais, armazém e compras;

- App Scribing avançado, combinação de contornos de marcação específica para facilitar armação.

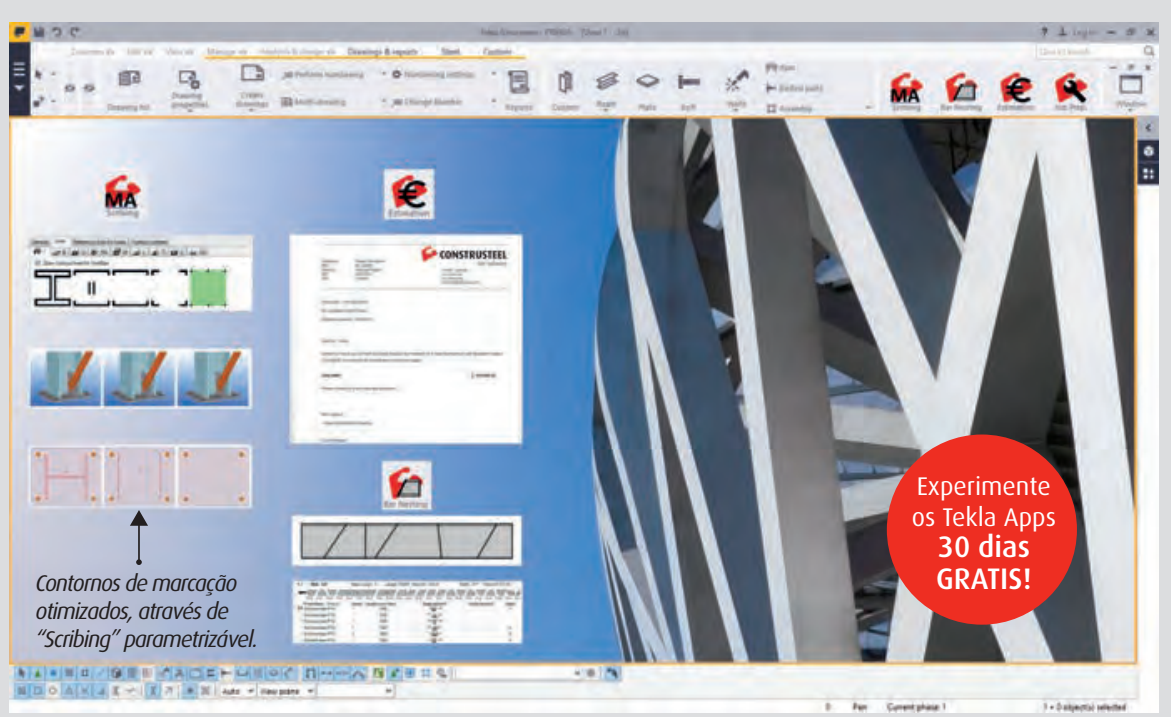

WWW.CONSTRUSTEEL.COM 